\title{
Oxygen-sensing by ion channels and mitochondrial function in carotid body glomus cells
}

José López-Barneo, Patricia Ortega-Sáenz, José I. Piruat and María García-Fernández

Laboratorio de Investigaciones Biomédicas, Departamento de Fisiología and Hospital Universitario Virgen del Rocío, Universidad de Sevilla, Sevilla, Spain

\begin{abstract}
Carotid body glomus cells release transmitters in response to hypoxia due to the increase of excitability resulting from inhibition of $\mathrm{O}_{2}$-regulated $\mathrm{K}^{+}$channels. The mechanisms involved in the detection of changes of $\mathrm{O}_{2}$ tension are unknown. Inhibition of the mitochondrial electron transport chain (ETC) at proximal and distal complexes induces external $\mathrm{Ca}^{2+}$-dependent catecholamine secretion. At saturating concentration of the ETC inhibitors, the cellular response to hypoxia is maintained. However, rotenone, a complex I blocker, selectively occludes the responsiveness to hypoxia of glomus cells in a dosedependent manner. The effect of rotenone is not mimicked by complex I inhibitors acting on different sites. We have also generated a knock-out mouse lacking SDHD, the small membrane-anchoring protein of the succinate dehydrogenase (complex II) of the mitochondrial electron transport chain. Homozygous $S d h d^{--}$animals die at early embryonic stages. Heterozygous $S d h d^{+/-}$mice show a general, non-compensated, deficiency of complex II activity, and abnormal enhancement of resting carotid body secretion rate due to decrease of $\mathrm{K}^{+}$conductance and persistent $\mathrm{Ca}^{2+}$ influx into glomus cells. However, responsiveness to hypoxia of carotid bodies from $S d h d^{+/-}$mice remains intact. These data strongly suggest that sensitivity to hypoxia of carotid body glomus cells is not linked in a simple way to mitochondrial electron flow. Nevertheless, it is possible that a rotenone-sensitive molecule critically participates in acute carotid body oxygen sensing.
\end{abstract}

2005 Signalling pathways in acute oxygen sensing. Wiley, Chichester (Novartis Foundation Symposium 272) p $54-72$

The carotid body (CB) is a major arterial chemoreceptor that senses blood $\mathrm{O}_{2}$ to evoke hyperventilation and sympathetic activation in response to hypoxemia (for a review see López-Barneo et al 2001). The $\mathrm{O}_{2}$-sensing elements in the $\mathrm{CB}$ are neurosecretory glomus, or type I, cells, which are organized in innervated clusters in close contact with blood vessels. Glomus cells are electrically excitable and have several types of $\mathrm{O}_{2}$-sensitive $\mathrm{K}^{+}$channels in their membranes (López-Barneo et al 1988, Delpiano \& Hescheler 1989, Peers 1990, Stea \& Nurse 1991, Buckler 1997). Although the $\mathrm{O}_{2}$-sensitive $\mathrm{K}^{+}$channel type can change in the different animal 
species, it is broadly accepted that inhibition of the membrane $\mathrm{K}^{+}$conductance by low $\mathrm{O}_{2}$ tension $\left(\mathrm{pO}_{2}\right)$ is the critical event leading to depolarization, external $\mathrm{Ca}^{2+}$ influx and activation of neurotransmitter release, which, in turn, stimulates the afferent sensory fibres. This 'membrane model' of chemotransduction, suggested by the electrophysiological experiments, has been confirmed by monitoring cytosolic $\left[\mathrm{Ca}^{2+}\right]$ and quantal catecholamine secretion in single dye-loaded cells (LópezBarneo et al 1993, Buckler \& Vaughan-Jones 1994, Ureña et al 1994, Montoro et al 1996, Carpenter et al 2000, Pardal et al 2000).

Despite the progress in glomus cell physiology the nature of the mechanisms coupling changes of $\mathrm{pO}_{2}$ to $\mathrm{K}^{+}$channel activity remain unknown. $\mathrm{CB}$ research is hampered by the small size of the organ and the difficulty to obtain a preparation with reproducible sensitivity to hypoxia, since this is a property easily lost by the cells. Because modulation of some $\mathrm{K}^{+}$channels by $\mathrm{pO}_{2}$ is seen in excised patches (Ganfornina \& López-Barneo 1991, Riesco-Fagundo et al 2001) it was postulated that $\mathrm{O}_{2}$ sensing in glomus cells depends on membrane-delimited mechanisms. In fact, membrane bound haeme oxygenase 2 has recently been suggested to mediate $\mathrm{O}_{2}$ sensitivity of heterologously expressed and glomus cell maxi- $\mathrm{K}^{+}$channels (Williams et al 2004). On the other hand, several investigators have traditionally considered mitochondria as the major players in $\mathrm{CB} \mathrm{O}_{2}$ sensing because, similarly to hypoxia, inhibitors of the electron transport chain (ETC) or mitochondrial uncouplers increase the afferent activity of the sinus nerve (see, for instance, Mills \& Jöbsis 1972). It has also been reported that cyanide and anoxia release $\mathrm{Ca}^{2+}$ from mitochondria in isolated rabbit glomus cells (Biscoe \& Duchen 1990, Duchen \& Biscoe 1992). Although the 'membrane model' of CB chemostransduction is unquestioned, the interest on mitochondria has resurged in recent years since mitochondrial uncouplers raise cytosolic $\mathrm{Ca}^{2+}$ and reduce background $\mathrm{K}^{+}$permeability in rat CB cells (Buckler \& Vaughan-Jones 1998). In addition, mutations in the small membrane-anchoring protein of succinate dehydrogenase (SDHD) in mitochondrial complex II are the main cause of familiar hereditary paraganglioma (PGL) a mostly benign, highly vascularized tumour of the CB (Baysal et al 2000). Similar to $\mathrm{CB}$ of individuals exposed chronically to hypoxia, PGL tumours display cellular hyperplasia/anaplasia. Moreover, the prevalence of PGL in individuals with SDHD mutations increases in high-altitude living populations (Astrom et al 2003). Thus, it has been proposed that SDHD participates in $\mathrm{O}_{2}$ sensing and that PGL tumours are induced by defects in the detection of blood $\mathrm{O}_{2}$ levels (Baysal et al 2000, Gimenez-Roqueplo et al 2001). It is, therefore, plausible that mitochondria are the site for glomus cell $\mathrm{O}_{2}$ sensing and that in response to hypoxia they signal the membrane to modulate $\mathrm{K}^{+}$channel activity.

Herein, we summarize recent work in our laboratory designed to investigate whether sensitivity of intact glomus cells to hypoxia is altered by mitochondrial dysfunction induced either pharmacologically (Ortega-Sáenz et al 2003) or by 
deletion of the SDHD gene (Piruat et al 2004). We describe the effect of mitochondrial ETC inhibition on glomus cell $\mathrm{K}^{+}$conductances and responsiveness to low $\mathrm{pO}_{2}$ as well as the physiological features of $\mathrm{CB}$ glomus cells from $S d h d$ knockout mice.

\section{Experimental procedures}

Most of the experiments were performed using the carotid body thin slice preparation in which the response of glomus cells to low $\mathrm{pO}_{2}$ can be studied in almost optimal physiological conditions (Pardal et al 2000, Pardal \& López-Barneo 2002). Amperometric recordings of catecholamine released from rat or mouse CB slices as well as patch clamp studies on isolated glomus cells were carried out following the procedures previously described (Ortega-Sáenz et al 2003, Piruat et al 2004). Changes in the solution composition or experimental conditions not previously published are indicated in the figure legends. Generation and genetic characterization of the $S d h d$ knockout mice are described in Piruat et al (2004).

\section{Results and discussion}

\section{Glomus cell sensitivity to bypoxia and pharmacological ETC inbibition}

In rat $\mathrm{CB}$ slices hypoxia (switching from a solution with a $\mathrm{pO}_{2}$ of $150 \mathrm{mmHg}$ to another with $\approx 15 \mathrm{mmHg}$ ) induced catecholamine release in an external $\mathrm{Ca}^{2+}$ dependent manner (Fig. 1A). Similar to hypoxia, exposure of glomus cells to ETC inhibitors also produced an external $\mathrm{Ca}^{2+}$-dependent secretory response. The effect is shown for rotenone and cyanide (inhibitors of complex I and IV, respectively) in Fig. 1B \& C, but it was also observed with blockers of complex II (thenoyltrifluoroacetone; TTFA) and III (myxothiazol and antimycin A) (Ortega-Sáenz et al 2003). The interaction between hypoxia and the mitochondrial electron flow was studied in cells exposed to low $\mathrm{pO}_{2}$ before and during application of ETC inhibitors. The rationale behind these experiments was that if hypoxia exerts its effect through alteration of the mitochondrial electron flow, preincubation with saturating concentrations of ETC blockers would prevent any further effect of low $\mathrm{pO}_{2}$. In contrast, the effects of hypoxia and ETC inhibition would be additive, at least partially, if they were acting through separate pathways. With the exception of rotenone, that occluded sensitivity to hypoxia (Fig. 1E), the ETC tested evoked secretory responses that were additive with that elicited by hypoxia (Fig. 1D-F). The differential effect of rotenone is particularly evident when the cumulative secretion signals recorded during concomitant exposure to the ETC inhibitors and hypoxia are shown at an expanded time base (right panels in Fig. $1 \mathrm{D} \& \mathrm{E}$ ). The effect of rotenone was observed in all the cells studied $(n=28)$ with concentrations of the drug between 
A
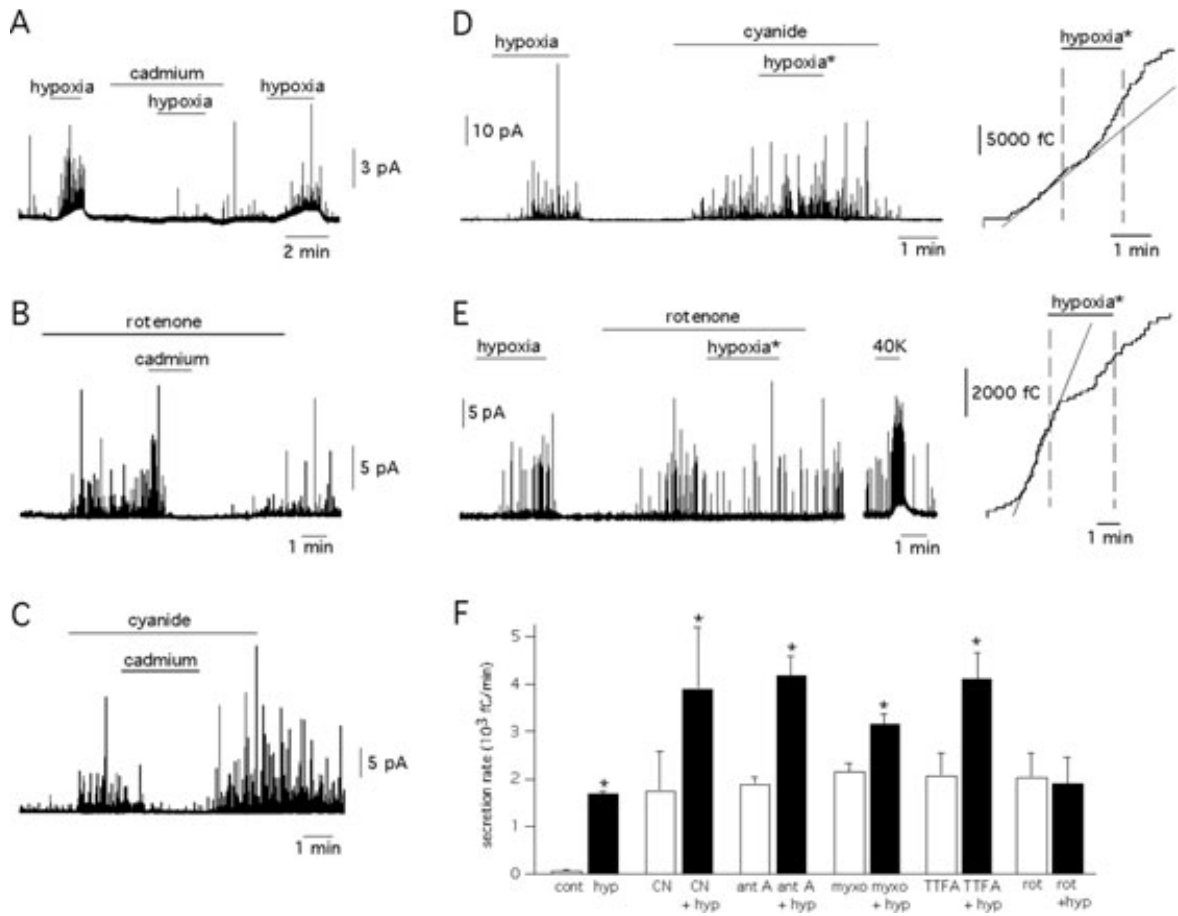

FIG. 1. Secretory responses of glomus cells to hypoxia and to the inhibition of the mitochondrial electron transport. (A-C) Amperometric signals showing catecholamine release from a glomus cell exposed to either hypoxia $(\approx 20 \mathrm{mmHg})$ or to electron transport inhibitors $(5 \mu \mathrm{M}$ rotenone and $100 \mu \mathrm{M}$ cyanide). Each spike represents an exocytotic event. In all cases secretion is reversibly abolished by external application of $0.3 \mathrm{mM}$ cadmium. (D, E) Secretory responses of glomus cells exposed concomitantly to hypoxia $\left(\mathrm{pO}_{2} \approx 20 \mathrm{mmHg}\right)$ and to cyanide $(100 \mu \mathrm{M})$ or rotenone $(5 \mu \mathrm{M})$. Left panels in $\mathrm{D} \& \mathrm{E}$ are the amperometric recordings, right panels are the cumulative secretion signals (in femtocoulombs) before, during, and after the exposure to hypoxia in the presence of the ETC inhibitors. The exposures to hypoxia are marked with an asterisk in the left panels. The straight lines represent the slopes (secretion rates) of the cumulative secretion signals immediately before the exposure to hypoxia. (F) Average secretion rate (ordinate in femtocoulombs $/ \mathrm{min}$, mean $\pm \mathrm{SE}$ ) measured in cells in various experimental conditions. From left to right: Control $\left(\mathrm{pO}_{2} \approx 150 \mathrm{mmHg}, n=17\right.$ cells) and hypoxia $\left(\mathrm{pO}_{2} \approx 20 \mathrm{mmHg}, n=17\right.$ cells). Cyanide and cyanide plus hypoxia $(100 \mu \mathrm{M}, n=4$ cells). Antimycin A ( 0.1 to $1 \mu \mathrm{g} / \mathrm{ml}, n=13$ cells $)$ and antimycin A plus hypoxia ( $n=7$ cells). Myxothiazol ( 0.1 to $1 \mu \mathrm{g} / \mathrm{ml}, n=6$ cells $)$ and myxothiazol plus hypoxia ( $n=6$ cells). TTFA ( 0.1 to $0.3 \mu \mathrm{M}, n=5$ cells) and TTFA plus hypoxia $(n=5$ cells). Rotenone ( 0.1 to $5 \mu \mathrm{M}, n=14$ cells), rotenone plus hypoxia ( $n=12$ cells). Asterisks indicate statistically significant difference $(P<0.05)$ between each pair of samples. 
0.1 and $5 \mu \mathrm{M}$ and was mimicked by 1-methyl-4-phenylpyridinium ion (MPP+) (which binds to the same site as rotenone) but not by other drugs (as rhein or diophenyleneiodonium) acting on different sites in mitochondrial complex I (OrtegaSáenz et al 2003). These data suggested that ETC inhibition and hypoxia might act through separate signalling pathways. However, rotenone, at concentrations that fully block complex I (Degli Esposti 1998, Vaux et al 2001) or saturate rotenone binding sites (Higgins \& Greenamyre 1996) selectively occludes responsiveness to hypoxia in $\mathrm{CB}$ cells. Therefore, it seems that a rotenone (and MPP+)-inhibitable molecule participates critically in $\mathrm{CB} \mathrm{O}_{2}$ sensing.

To further investigate the effect of ETC inhibitors on glomus cells, we recorded ionic currents from patch clamped cells using the perforated patch-clamp technique. Although the action of the ETC inhibitors tested in this set of experiments was rather variable, their most common qualitative effects are summarized on Fig. 2. Rotenone, antimycin A and cyanide all produced a marked reduction in the amplitude of the $\mathrm{K}^{+}$currents that, particularly in the case of antimycin A, was frequently irreversible (Fig. 2A). Application of depolarizing ramps demonstrated that besides

A
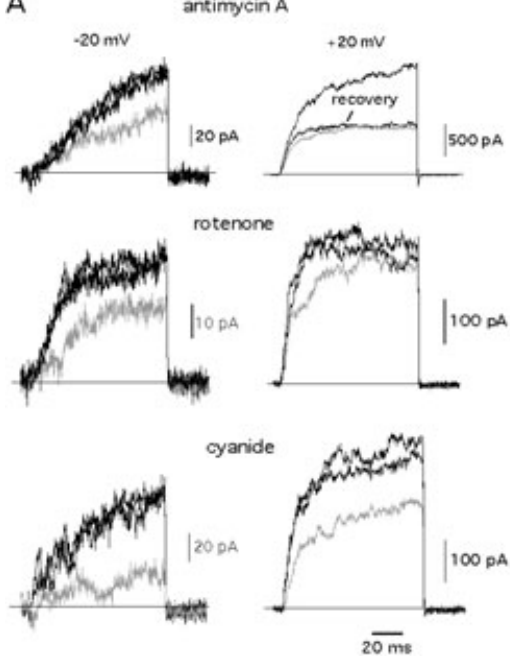

B
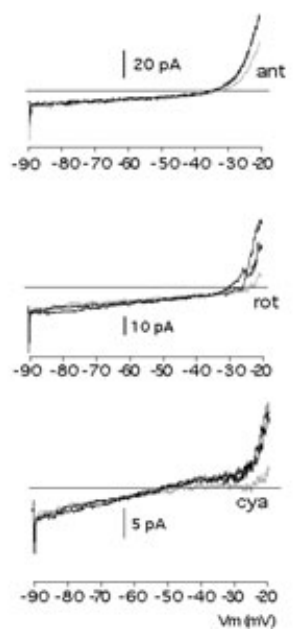

C
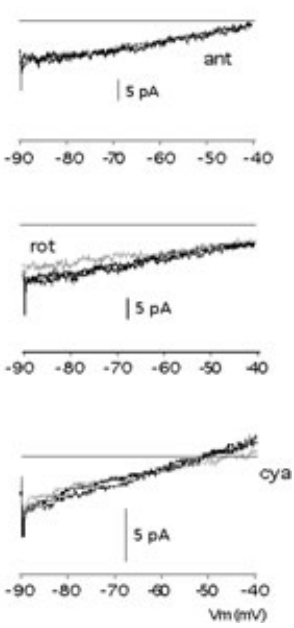

FIG. 2. Electrophysiological effects of mitochondrial inhibitors on dispersed rat glomus cells. (A) Macroscopic $\mathrm{K}^{+}$currents recorded from perforated patch clamped cells subjected to step depolarization to the indicated membrane potentials (holding potential, $-80 \mathrm{mV}$ ). Control and recovery traces are in black. Traces recorded in the presence of antimycin A $(1 \mu \mathrm{g} / \mathrm{ml})$, rotenone $(3 \mu \mathrm{M})$ or cyanide $(100 \mu \mathrm{M})$ are in grey. (B, C) Currents recorded during the application of depolarizing voltage ramps in perforated patch clamped glomus cells. Experimental conditions as in $\mathrm{A}$. 
the effects on voltage-dependent outward current amplitude, rotenone and cyanide also reduced membrane resting conductance and displaced to more positive potentials the zero current level (Fig. 2B \& C). These observations suggested that, as indicated by Wyatt \& Buckler (2004), the two agents decrease background $\mathrm{K}^{+}$ conductance. In contrast, antimycin A $(1 \mu \mathrm{g} / \mathrm{ml})$ had no affect on the resting conductance of glomus cells (Fig. 2C). Hence, antimycin A and cyanide, which have similar effects on secretion, have different actions on the resting $\mathrm{K}^{+}$conductance. Rotenone and cyanide, with almost identical electrophysiological effects influenced in different ways the $\mathrm{O}_{2}$ sensitivity of the glomus cells. These data suggest that glomus cell secretion induced by the ETC inhibitors is probably the result of the pharmacological effect of these drugs on $\mathrm{K}^{+}$channels, unrelated to their effect on the mitochondrial electron transport. In fact, rotenone reversibly inhibits the macroscopic $\mathrm{K}^{+}$currents in cells devoid of mitochondria (Searle et al 2002).

\section{Persistent carotid body activation with normal glomus cell responsiveness to bypoxia in partially Sdhd-deficient mice}

To evaluate the participation of mitochondrial complex II in $\mathrm{CB} \mathrm{O}_{2}$ sensing, we have generated a mouse model lacking SDHD, a component of succinate dehydrogenase (Piruat et al 2004). SDHD deficiency is the most frequent manifestation of the hereditary paraganglioma (PGL, Baysal 2003), a catecholamine-secreting tumour in the neck affecting the carotid body (CB). PGL tumours display cellular hyperplasia/anaplasia similar to the $\mathrm{CB}$ of individuals exposed to chronic hypoxia (Lahiri et al 2000, Wang \& Bisgard 2002), thus it has been proposed that the ultimate cause of PGL tumours is a defect in sensing environmental $\mathrm{O}_{2}$ levels (Baysal et al 2000, Gimenez-Roqueplo et al 2001, Rustin et al 2002, Baysal 2003). We have tested in young adult mice whether partial $S d h d$ deficit and inhibition of mitochondrial complex II activity alter CB function by monitoring single-cell secretory activity in slices of the whole organ. Similar to rat CB slices (Pardal et al 2000, Ortega-Sáenz et al 2003), the response to hypoxia of glomus cells in mouse CB slices was characterized by a sharp and reversible burst of secretory events (Fig. $3 \mathrm{~A}$ ). This response was maintained, or even augmented, in $S d h d^{+/-}$mice (Fig. 3B-C), indicating that partial deficiency of complex II activity does not seem to alter glomus cell responsiveness to hypoxia. However, spontaneous CB activity in normoxic conditions was increased by $\sim 2.4$-fold (statistical significance, $P<0.05$ ) in $S d h d^{+/-}$animals as compared with wild-type littermates (Fig. 3D). The higher resting excitability of $\mathrm{CB}$ cells in $S d h d^{+/-}$animals also explained the slight increase of the hypoxic response. The spontaneous secretory activity of $S d h d^{+/-}$glomus cells was reversibly abolished by blockade of $\mathrm{Ca}^{2+}$ channels with $\mathrm{Cd}^{2+}$ (Fig. 3E), thus suggesting that it was due to persistent extracellular $\mathrm{Ca}^{2+}$ influx through membrane channels (Pardal et al 2000, Ortega-Sáenz et al 2003). 
A

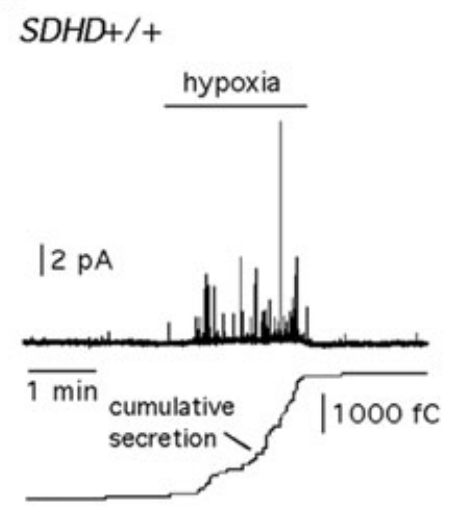

C

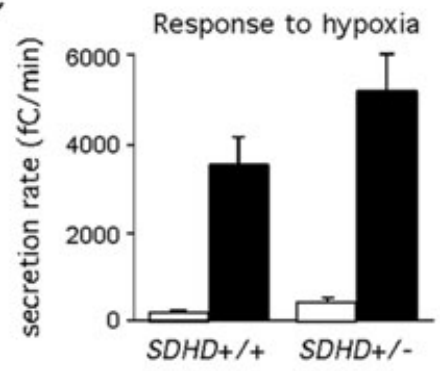

B

$S D H D+/-$
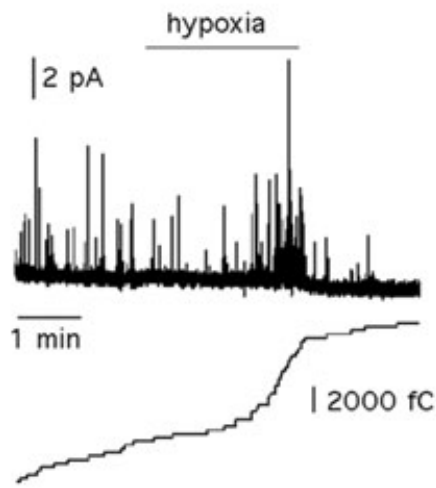

D

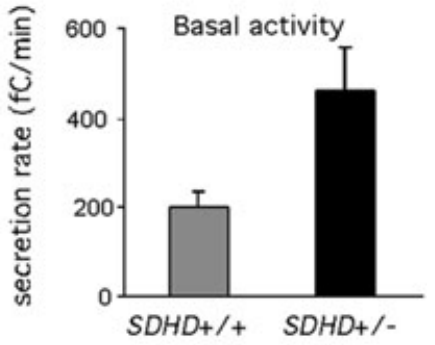

E

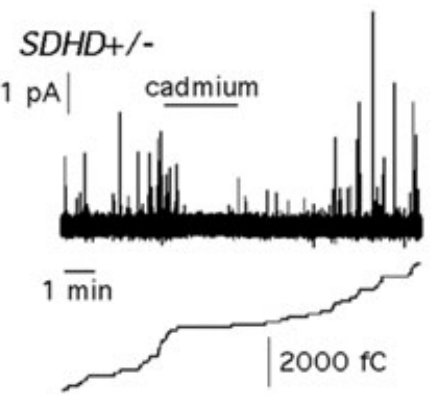

FIG. 3. Secretory activity and responsiveness to hypoxia of carotid body glomus cells. (A, B) Secretory response to hypoxia of glomus cells of $S d h d^{+/+}$and $S d h d^{+/-}$mice. Cumulative secretion (in fC) for each experiment are shown. (C) Quantification of the secretory response to low $\mathrm{O}_{2}$ tension (in $\mathrm{fC} /$ last min hypoxia) of SDHD deficient (mean $\pm \mathrm{SE}, n=16)$ and wild-type $(n=18)$ mice. Anova test, $P=0.12$. (D) Quantification of the spontaneous secretory activity in a carotid body slice from $S d h d^{+/+}$(mean $\left.\pm \mathrm{SE}, n=16\right)$ and wild-type $(n=18)$ mice. Kruskal-Wallis test, $P=0.01$. (E) Spontaneous secretory activity in a $S d h d^{+/-}$glomus cell and reversible blockade by application of $0.3 \mathrm{mM}$ extracellular cadmium. 
The constitutive functional activation of $\mathrm{CB}$ glomus cells observed in $S d h d-$ deficient mice occurred with only minor morphological changes in CB structure, without obvious organ enlargement or gross histological modifications. We have only observed a slight, although significant, increase in the percentage of glomus cells, identified by their immunoreactivity to tyrosine hydroxylase $(\mathrm{TH})$, the ratelimiting enzyme for catecholamine synthesis (Piruat et al 2004). These subtle glomus cell hyperplasia probably precede $\mathrm{CB}$ tumour transformation. In humans, loss of heterozygosity $(\mathrm{LOH})$ of the wild-type allele is required for PGL to occur (Baysal et al 2000, Baysal 2003). The absence of tumours in the $S d h d^{+/-}$mice suggests that the induction of $\mathrm{LOH}$ in $\mathrm{CB}$ glomus cells depends on different factors in humans and rodents.

\section{Decrease of glomus cell $\mathrm{K}^{+}$current density in $\mathrm{S} d \mathrm{~d}^{+/-}$mice}

We have studied the $\mathrm{K}^{+}$currents in voltage clamped glomus cells, as it is known that in this preparation $\mathrm{K}^{+}$channels regulate membrane potential and cellular excitability (see Pardal et al 2000 and references therein). Representative families of $\mathrm{K}^{+}$currents recorded from $S d h d^{+/+}$and $S d h d^{+/-}$glomus cells using the perforated patch clamp technique are illustrated in Fig. $4 \mathrm{~A}, \mathrm{~B}$. The average $\mathrm{K}^{+}$current densityvoltage relationships are shown in Fig. 4C. Although other changes in the $\mathrm{K}^{+}$currents have been reported before (see Piruat et al 2004), the most obvious and consistent modification induced by partial deletion of the $S d h d$ gene was a reduction in total $\mathrm{K}^{+}$current density from $4.6 \pm 1.5 \mathrm{pA} / \mu \mathrm{m}^{2}, n=6$ in $S d h d^{+/+}$to $2.5 \pm$ $0.8 \mathrm{pA} / \mu \mathrm{m}^{2}, n=6$ for $S d h d^{+/-}$, at $+20 \mathrm{mV}$. It is known that $\mathrm{Ca}^{2+}$-activated $\mathrm{K}^{+}$channels contribute to the macroscopic voltage-dependent $\mathrm{K}^{+}$current and the resting potential of rodent glomus cells (Wyatt \& Peers 1995, Pardal et al 2000), and that in most tissues these channels act as counter-regulatory devices that prevent excessive cell depolarization. Therefore, the biophysical changes observed in patch clamped $S d h d^{+/-}$glomus cells could account for the persistent secretory activity detected in intact cells by amperometry.

\section{Conclusions}

Our data indicate that, as hypoxia, ETC inhibitors induce a secretory response in carotid body glomus cells, which is dependent on extracellular $\mathrm{Ca}^{2+}$. They also suggest that sensitivity to hypoxia of carotid body glomus cells is not linked in a simple way to mitochondrial electron flow. In fact, all the ETC inhibitors tested have a non-specific pharmacological action as blockers of voltage-gated $\mathrm{K}^{+}$channels. However, a rotenone (and $\mathrm{MPP}^{+}$)-sensitive molecule, located either inside or outside mitochondria, appears to participate in acute oxygen sensing in the carotid body. Partial genetic deficiency of mitochondrial complex II due to Sdhd deletion 


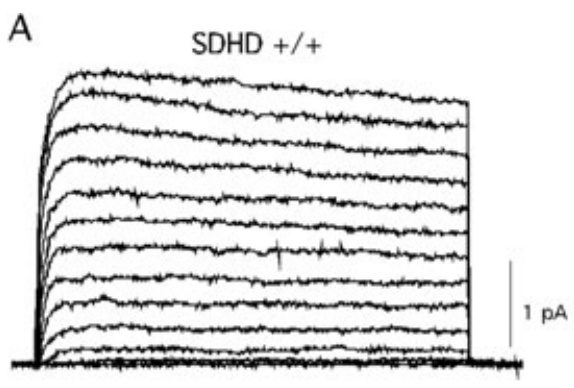

C
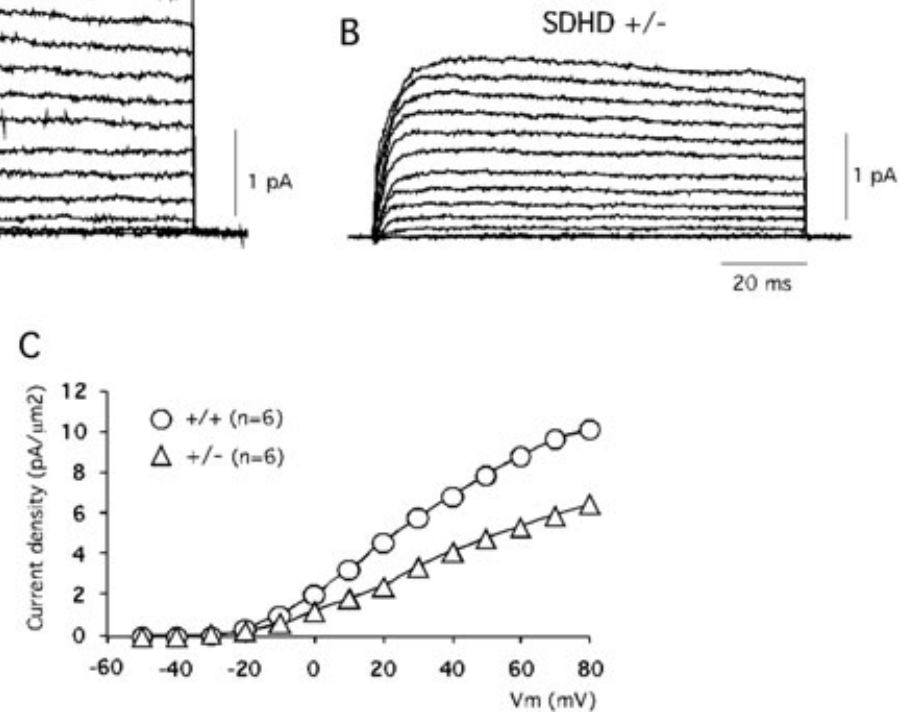

FIG. 4. Macroscopic $\mathrm{K}^{+}$currents in patch clamped dispersed glomus cells of wild-type and SDHD-partially deficient mice. (A, B) Families of representative outward $\mathrm{K}^{+}$currents recorded in $S d h d^{+/+}$and $S d h d^{+/-}$glomus cells during $100 \mathrm{~ms}$ depolarizing pulses reaching membrane potentials between -40 and $+80 \mathrm{mV}$ in steps of $10 \mathrm{mV}$. C. $\mathrm{K}^{+}$current density (ordinate) versus voltage (abscissa) relationship in wild-type (circles) and $S d h d^{+/-}$(triangles) glomus cells. Each point is the average of six different experiments.

produces persistent carotid body glomus cell activation and a decrease of $\mathrm{K}^{+}$ channel current density. Sensitivity to hypoxia of these cells was, however, unaltered.

\section{Acknowledgements}

J. López-Barneo received the 'Ayuda a la Investigación 2000' of the Juan March Foundation. Research was also supported by The Lilly Foundation and by grants of the Andalusian Government, Spanish Ministries of Health and of Science and Technology.

\section{References}

Astrom K, Cohen JE, Willett-Brozick JE et al 2003 Altitude is a phenotypic modifier in hereditary paraganglioma type 1: evidence for an oxygen-sensing defect. Hum Genet 113:228-237 
Baysal BE 2003 On the association of succinate dehydrogenase mutations with hereditary paraganglioma. Trends Endocrinol Metab 14:453-459

Baysal BE, Ferrell RE, Willett-Brozick JE et al 2000 Mutations in SDHD, a mitochondrial complex II gene in hereditary paraganglioma. Science 287:848-851

Biscoe TJ, Duchen MR 1990 Responses of type I cells dissociated from the rabbit carotid body to hypoxia. J Physiol 428:39-59

Buckler KJ 1997 A novel oxygen-sensitive potassium current in rat carotid body type I cells. J Physiol 498:649-662

Buckler KJ, Vaughan-Jones RD 1994 Effects of hypoxia on membrane potential and intracellular calcium in rat neonatal carotid body type I cells. J Physiol 476:423-428

Buckler KJ, Vaughan-Jones RD 1998 Effects of mitochondrial uncouplers on intracellular calcium, $\mathrm{pH}$ and membrane potential in rat carotid body type I cells. J Physiol 513:819-833

Carpenter E, Hatton CJ, Peers C 2000 Effects of hypoxia and dithionite on catecholamine release from isolated type I cells of the rat carotid body. J Physiol 523:719-729

Degli Esposti M 1998 Inhibitors of the NADH-ubiquinone reductase: an overview. Biochim Biophys Acta 1364:222-235

Delpiano MA, Hescheler J 1989 Evidence for a $\mathrm{pO}_{2}$-sensitive $\mathrm{K}^{+}$channel in the type-I cell of the rabbit carotid body. FEBS Lett 249:195-198

Duchen MR, Biscoe TJ 1992 Relative mitochondrial membrane potential and $\left[\mathrm{Ca}^{2+}\right]_{\mathrm{i}}$ in type I cells isolated from the rabbit carotid body. J Physiol 450:33-61

Ganfornina MD, López-Barneo J 1991 Single $\mathrm{K}^{+}$channels in membrane patches of arterial chemoreceptor cells are modulated by $\mathrm{O}_{2}$ tension. Proc Natl Acad Sci USA 88:29272930

Gimenez-Roqueplo AP, Favier J, Rustin P et al 2001 The R22X mutation of the SDHD gene in hereditary paragaglioma abolishes the enzymatic activity of complex II in the mitochondrial respiratory chain and activates the hypoxia pathway. Am J Hum Genet 69:1186-1197

Higgins DS, Greenamyre JT $1996\left[{ }^{3} \mathrm{H}\right]$ dihydrorotenone binding to NADH: Ubiquinone reductase (complex I) of the electron transport chain: An autoradiographic study J Neurosci 16:3807-3816

Lahiri S, Prabhakar NR, Forster RE 2000 Oxygen sensing. Molecule to man, Kluwer Academic/Plenum Publishers, New York, NY, USA

López-Barneo J, López-López JR, Ureña J et al 1988 Chemotransduction in the carotid body: $\mathrm{K}^{+}$ current modulated by $\mathrm{pO}_{2}$ in type I chemoreceptor cells. Science 241:580-582

López-Barneo J, Benot AR, Ureña J 1993 Oxygen sensing and the electrophysiology of arterial chemoreceptor cells. News Physiol Sci 8:191-195

López-Barneo J, Pardal R, Ortega-Sáenz P 2001 Cellular mechanism of oxygen sensing. Annu. Rev. Physiol. 63:259-287

Mills E, Jöbsis FF 1972 Mitochondrial respiratory chain of carotid body and chemoreceptor response to changes in oxygen tension. J Neurophysiol 35:405-428

Montoro RJ, Ureña J, Fernández-Chacón R et al 1996 Oxygen sensing by ion channels and chemotransduction in single glomus cells. J Gen Physiol 107:133-143

Ortega-Sáenz P, Pardal R, García-Fernández M et al 2003 Rotenone selectively occludes sensitivity to hypoxia in rat carotid body glomus cells. J Physiol 548:789-800

Pardal R, López-Barneo J 2002 Low glucose-sensing cells in the carotid body. Nature Neurosci 5:197-198

Pardal R, Luwewig U, García-Hirschfeld J et al 2000 Secretory responses of intact glomus cells in thin slices of rat carotid body to hypoxia and tetraethylammonium. Proc Natl Acad Sci USA 97:2361-2366

Peers C 1990 Hypoxic suppression of $\mathrm{K}^{+}$currents in type I carotid body cells: selective effect on the $\mathrm{Ca}^{2+}$-activated $\mathrm{K}^{+}$current. Neurosci Lett 119:253-256 
Piruat JI, Pintado CO, Ortega-Saenz P et al 2004 The mitochondrial SDHD gene is required for early embryogenesis, and its partial deficiency results in persistent carotid body glomus cells activation with full responsiveness to hypoxia Mol Cell Biol 24:10933-10940

Riesco-Fagundo AM, Pérez-García MT, González C et al $2001 \mathrm{O}_{2}$ modulates large conductance $\mathrm{Ca}^{2+}$-dependent $\mathrm{K}^{+}$channels of rat chemoreceptor cells by a membrane-restricted and COsensitive mechanism. Circ Res 89:430-436

Rustin P, Munnich A, Rötig A 2002 Succinate dehydrogenase and human diseases: new insights into a well-known enzyme. Eur J Hum Genet 10:289-291

Searle GJ, Hartness ME, Hoareau R et al 2002 Lack of contribution of mitochondrial electron transport to acute $\mathrm{O}_{2}$ sensing in model airway chemoreceptors. Biochem Biophys Res Comm 291:332-337

Stea A, Nurse CA 1991 Whole-cell and perforated-patch recordings from $\mathrm{O}_{2}$-sensitive rat carotid body cells grown in short- and long-term culture. Pflügers Arch Eur J Physiol 418:93-101

Ureña J, Fernández-Chacón R, Benot AR, et al 1994 Hypoxia induces voltage-dependent $\mathrm{Ca}^{2+}$ entry and quantal dopamine secretion in carotid body glomus cells. Proc Natl Acad Sci USA 91:10208-10211

Vaux EC, Metzen E, Yeates KM et al 2001 Regulation of hypoxia inducible factor is preserved in the absence of a functioning mitochondrial respiratory chain. Blood 98:296-302

Wang ZY, Bisgard GE 2002 Chronic hypoxia-induced morphological and neurochemical changes in the carotid body. Microsc Res Tech 59:168-177

Williams SE, Wootton P, Mason HS et al 2004 Hemoxygenase-2 is an oxygen sensor for a calcium sensitive potassium channel. Science 306:2093-2097

Wyatt CN, Peers C $1995 \mathrm{Ca}^{2+}$-activated $\mathrm{K}^{+}$channels in isolated type I cells of the neonatal rat carotid body. J Physiol 483:559-565

Wyatt CN, Buckler KJ 2004 The effect of mitochondrial inhibitors on membrane currents in isolated neonatal rat carotid body type I cells. J Physiol 556:175-191

\section{DISCUSSION}

Weir: What temperature were your experiments done at, and does it matter whether you do them at room temperature?

López-Barneo: All the experiments on carotid body slices are done at between 34 and $36^{\circ} \mathrm{C}$. The experiments in dispersed cells were done at room temperature. At room temperature the slices also respond to hypoxia, but the effect is slower and less potent.

Weir: Was the membrane potential depolarised with any of the mitochondrial inhibitors?

López-Barneo: I can't remember. But I suspect that those decreasing $\mathrm{K}^{+}$conductance would depolarise the membranes. I am not sure about antimycin A. We haven't measured directly the membrane potential in response to metabolic activity.

Weir: Is the additional rotenone effect in ablating the hypoxic effect related to its ability to cause depolarization?

López-Barneo: I can't answer that, since we have not performed this type of experiment.

Buckler: Your ion channel experiments were all in perforated patch. So how do you know that the effects of rotenone or antimycin on your channels are non- 
selective and non-specific, as opposed to being mediated via an effect upon on the mitochondria?

López-Barneo: We did whole-cell recording in perforated patches and measured the $\mathrm{K}^{+}$currents. Antimycin $\mathrm{A}$, rotenone and cyanide all produce, in addition, to mitochondrial inhibition blockade of $\mathrm{K}^{+}$channels. We don't see any major difference between them. However, when we do the experiment using the same concentration in the slices we see a differential effect with each. All three activate the carotid body, but only rotenone will block the sensitivity to hypoxia. The way we interpret this is that what we are seeing in the whole cell recording is a pharmacological action. I am concerned about the use of these drugs without testing what else they do. When you say a molecule is a mitochondrial inhibitor, it can do many other things. One thing that interests us is the differential effect of antimycin A, rotenone and cyanide.

Buckler: Did you do a dose-response for antimycin A or cyanide with respect to the hypoxia effect? With rotenone, whether you got additivity (with hypoxia) or not depended on the concentration of rotenone you used. Did you do the same for cyanide or antimycin A? If you push the concentration of antimycin or cyanide up higher can you saturate the response?

López-Barneo: We haven't done this. In our hands, if we go to high concentrations of cyanide we see a response due to release of calcium from internal stores and therefore you can't do the experiment. With antimycin A, the concentration we are using is already non-reversible.

Buckler: Just because you get $\mathrm{Ca}^{2+}$ release from internal stores doesn't mean that you can't do the experiment. You are looking for additivity between hypoxia and metabolic inhibitors.

López-Barneo: In our hands, if we go to higher concentrations of cyanide we get $\mathrm{Ca}^{2+}$ release from the stores, massive secretion and irreversible damage to the cells.

Buckler: If you say that a higher concentration of antimycin is toxic, then this suggests to me that the concentration of antimycin you are using routinely is not toxic because it is probably insufficient to fully inhibit mitochondrial function. So how then can you take additivity between a sub maximal level of antimycin and hypoxia as evidence that hypoxia acts via a pathway independent of the mitochondrion?

López-Barneo: The assumption I made is that the drugs are used at saturating concentrations for electron chain inhibition. The doses we are using are at least five times higher than others have reported will inhibit the electron transport chain.

Murphy: I know nothing about carotid bodies, but the parallel between glucosestimulated insulin release in pancreatic $\beta$ cells and the response of the carotid body to hypoxia must be one that is familiar to you. In $\beta$ cells mitochondrial function affects the ATP/ADP ratio and thereby alters the $\mathrm{K}^{+}$channel and consequently activates the $\mathrm{Ca}^{2+}$ channel. In the carotid body an effect of oxygen on the 
ATP/ADP ratio could also act on the $\mathrm{K}^{+}$channel in a similar way. The critical thing is that the ATP/ADP ratio is the link, a mitochondrial way of signalling through a $\mathrm{K}^{+}$channel and then to a $\mathrm{Ca}^{2+}$ channel. If you could measure the ATP/ADP ratio in these cells during hypoxia that might be quite informative. This is easy to do even in very small numbers of cells because the assay is very sensitive. With respect to mitochondrial respiratory chain inhibitors, there is considerable evidence that many of these have secondary effects, in addition to inhibition of respiration: usually at concentrations considerably above the effect of the inhibitors on respiration. It seems important to me to first show that you have added just enough inhibitor to completely inhibit respiration and then determine whether the inhibitor is having an effect on the endpoint of interest. Then you can increase the concentration of the inhibitor to see if the inhibitor has secondary effects in addition to inhibition of respiration. For example, at low concentrations rotenone is known to inhibit complex I, but at higher concentrations it is thought to have a secondary effect and increase ROS production. Another example is antimycin which inhibits the cytochrome/Bcl1 complex, but at higher concentrations it also affects Bcl2 family proteins. To summarize, it seems critical to me to first be certain that the effects of the inhibitors are due solely to the inhibition of respiration.

López-Barneo: It is difficult to do this.

Murphy: I accept that it is technically tricky to measure respiration in small amounts of tissue, but you could achieve the same end by measuring a surrogate of respiration such as the ATP/ADP ratio, or cytochrome reduction levels, which are far easier to measure on small numbers of cells. Similarly, you also assess the membrane potential using a fluorescent probe such as JC1.

Buckler: Determining whether electron transport is fully blocked or not is actually quite easy in isolated cells. You use a fluorescent indicator of mitochondrial potential, fully depolarize the mitochondria with a suitable uncoupler and then see whether they can repolarize when you withdraw the uncoupler in the presence of which ever inhibitor of electron transport you are interested in (see e.g. Wyatt \& Buckler 2004).

López-Barneo: I don't think you can do a good measurement. We do have a drug that in addition to inhibiting mitochondrial electron transport will produce blockade of the $\mathrm{K}^{+}$channel. I don't think you can measure mitochondrial membrane potential in glomus cells.

Rich: I have a comment concerning the protocol for using these mitochondrial inhibitors. Do you have a continuous flow of a buffer with the inhibitor in it, in your experiments?

López-Barneo: Yes.

Rich: In this case it raises a difficult technical question that you have to address. The majority of these inhibitors, such as rotenone and antimycin A, have partition coefficients between the aqueous solution and the targeted membranes of $10^{8}$ or 
more for partitioning into the membrane compared with the liquid. Hence, if you are doing this addition in a cuvette and add $1 \mu \mathrm{M}$ rotenone, essentially all of the inhibitor will go into the membrane and almost none will be left free in solution. However, if you have a continuous flow, and you are continuously replenishing the rotenone, the inhibitor will continue to build up in the membranes until its concentration becomes astronomical. In fact, you can think of it as replacing a lipid membrane by a rotenone membrane! Secondary effects are therefore inevitable, which are not of any physiological relevance.

López-Barneo: That is my point. We are getting a high concentration of the drug. This is the basis of all our assumptions. But even in this situation there can be further sensitivity to hypoxia in the case of myxothiazol, antimycin A and cyanide but not in the case of rotenone.

Rich: Getting back to the technical aspects, you can look in the literature and see that rotenone has a binding constant of something like $10^{-9} \mathrm{M}$ for the complex I site. You might assume that you could add just 10 times that concentration to the cells and get $90 \%$ inhibition, which is true, but only if the inhibitor has unhindered access it its binding sites. But in practice, if you only add 10 times the $K_{\mathrm{m}}$ to cells, the rotenone firstly encounters the cell membrane and because the partition coefficient is $10^{8}$ or more towards the membrane, the rate constant of entry into the membrane is very fast but the rate constant out towards the mitochondrial sites can be hours. It enters the cell membrane, and you don't get any inhibition of mitochondrial respiration because of difficulty in equilibrating to the mitochondria. Hence, when you add $10 \mathrm{nM}$ rotenone to cells there is no effect on mitochondrial respiration even though this concentration is above the binding constant. It is not because there is a different affinity; it is because of the difficulty of delivering the drug to the site through the other membranes where it resides for a long time. All this needs to be taken into account when we are looking at these chemicals with a complex system such as a whole cell. There are great technical difficulties in titrating because any inhibition will be extremely time dependent.

López-Barneo: Of course, we care about these technical issues, but in fact the complications are working in our favour in the experiments. For example, relatively large concentrations of antimycin A put in the bath increases a lot of secretory activity because it is probably doing bad things to the cell, but it still isn't reducing sensitivity to hypoxia, whereas rotenone is having an effect.

Rich: But these are all artefactual effects from flooding the membranes with inhibitor.

López-Barneo: The sensitivity to hypoxia is a very sudden phenomenon in the cell. It is irreversible with rotenone. With the other drugs hypoxia will increase secretory activity, and when this is removed the effect of hypoxia disappears even when the drug remains. It could be that rotenone is not binding anywhere, of course. Hypoxia could be having some non-specific effect on the cell. We saw this a couple 
of years ago and since then we have been trying hard to get rotenone-binding sites outside mitochondria. It could be that this is a non-specific effect of hypoxia, though.

Rich: There are hundreds, perhaps thousands, of inhibitors that hit the rotenone site. It might be worth trying some of these.

López-Barneo: Other blockers of mitochondrial complex I didn't do this, but MTPT, which binds to the same site than rotenone on mitochondria, did.

Rich: Those two you mention are complicated ones that are non-specific, but you might consider some of the ultraspecific tight binding inhibitors. Some of them have unmeasurably tight binding constants.

Gurney: I have a question concerning the link between the $\mathrm{K}^{+}$channel, the $\mathrm{Ca}^{2+}$ channel and secretion. Do you just see a lack of reproducibility in the effect of hypoxia on $\mathrm{K}^{+}$current in the isolated cells, or is it also variable in the slices?

López-Barneo: More in the isolated cells, but it is still there in the slices.

Gurney: That makes me wonder whether $\mathrm{K}^{+}$channels actually mediate the secretory response, which seems robust. I wonder if the cadmium effect is due to block of non-selective cation channels rather than voltage-dependent $\mathrm{Ca}^{2+}$ channels. The ATP effect on the cells could be relevant here: although cytoplasmic ATP seemed to have a big effect on the $\mathrm{Ca}^{2+}$ current, you indicated that it doesn't seem to affect the secretory response. This would also tend to dissociate the $\mathrm{Ca}^{2+}$ channels from the secretory response. Could it be that voltage-gated $\mathrm{Ca}^{2+}$ channels are not necessarily a mediator?

Lopez-Barneo: We didn't measure the secretory response related to ATP. We measured the response to hypoxia in cells dialysed with and without ATP. We looked at the $\mathrm{Ca}^{2+}$ concentration.

Gurney: This wasn't affected, which makes me think that the rise in $\mathrm{Ca}^{2+}$ concentration is not due to the L-type $\mathrm{Ca}^{2+}$ channels. Could it be that non-selective cation channels are responsible?

López-Barneo: We have looked at the effect of hypoxia on cation channels. It doesn't affect them. People working on rat carotid body cells have shown that the macroscopic $\mathrm{K}^{+}$channels are inhibited by hypoxia or the resting potential background $\mathrm{K}^{+}$channels are inhibited by hypoxia, but no one has reported an increase in the cation conductance in response to hypoxia. We are now seeing that hypoglycaemia is producing an increase in this cation conductance.

Gurney: The effects on $\mathrm{K}^{+}$currents are really quite small. Is this enough to cause depolarization? They are small at quite positive potentials, so at the resting potential what would happen?

López-Barneo: This is ongoing question. The resting potential in the perforated patches is $40-50 \mathrm{mV}$. When we look carefully at the ramps to see where the voltage- 
gated $\mathrm{K}$ channels are activated, we can see that some channels are activated around $-40 \mathrm{mV}$. If we use TEA in these preparation this will produce depolarisation and increase secretory activity.

Gurney: Are the ramps you are looking at purely activating $\mathrm{K}^{+}$current?

López-Barneo: It could also be other cation current. The nature of the channel that is responsible for the receptor potential for the depolarization in carotid body cells is a question that has been debated over the last decade. I haven't been working on the rabbit carotid body for a decade now, but I find it very different from the rat carotid body. The rabbit carotid body contains a lot of $\mathrm{Na}^{+}$channels and carotid body cells in situ and at the oxygen concentration in the arterial blood probably fire action potentials repetitively. Voltage-dependent $\mathrm{K}^{+}$channels are probably more important in the rabbit than in the rat where resting potential $\mathrm{K}^{+}$channels are needed to initiate a depolarizing receptor potential.

Evans: I was wondering about the range of experiments you were presenting. If we disregard non-selective actions of the various mitochondrial inhibitors that you have used, you could have a varying degree of inhibition of mitochondrial function. This could underpin the variable effects on carotid body glomus cells of different mitochondrial inhibitors and the variability seen with respect to their ability to attenuate or not the response to hypoxia. Where the effect of glucose is concerned, the other issue that I'd like to raise is that rotenone may well block the response to hypoxia by cutting out the mitochondria. However, this doesn't necessarily mean that the signal transduction pathway utilized by glucose removal is different form that activated by hypoxia. By blocking the mitochondria you will increase a cell's reliance on glycolysis for ATP production. Any effect on cells of altering the glucose concentration could be mediated by the modulation of a metabolic signalling pathway sensitive, in some way, to changes in ATP supply. Such a pathway could be regulated by changes in the metabolic status of a cell by changes in glycolytic and/or mitochondrial ATP supply.

López-Barneo: We know that low glucose in carotid body cells produces an increase in secretory activity. This is dependent on the rise of internal $\mathrm{Ca}^{2+}$ concentration due to influx from the outside. In our preliminary voltage clamp experiment we showed that low glucose also inhibited the macroscopic $\mathrm{K}^{+}$current. We have found that in addition to this the more reproducible physiological effect of low glucose is a depolarizing receptor potential that is due to activation of resting non-selective cation conductance. This can be seen in the presence of TEA and iberiotoxin. This conductance is not affected by low $\mathrm{pO}_{2}$. It seems that a major mechanism for signalling low glucose is this cationic conductance. We know that this isn't related to glucose itself, because when glucose is replaced by O-methyl glucose (which is imported but which isn't phosphorylated or metabolized), there is no effect. We don't know what the signal generated as a consequence of glucose metabolism that 
is modulating the non-selective conductance in glomus cells. We have data showing that the non-selective cation conductance is activated by low glucose and produces a depolarization of the carotid body cell.

Gonzalez: Do you think that the difference between rotenone and the other mitochondrial inhibitors could be because rotenone inhibits the production of reactive oxygen species?

López-Barneo: We haven't looked at this. Although the experiments in which we load the cells with new internal solutions are very complicated, we could investigate the point you are raising by loading the cells with a large amount of DTT or another reducing agent. Of course, it could be that reactive oxygen species produced in mitochondria are signalling the membrane. However, it is interesting that rotenone is the only mitochondrial complex I inhibitor that in our preparation can occlude sensitivity to hypoxia. We cannot discard that somehow the mitochondrial complex I acts as an oxygen sensor. I would expect that both antimycin A and cyanide would increase the radical production at the rotenone site. However they behave differently with respect to the background $\mathrm{K}^{+}$channels (cyanide inhibits them and antimycin A appears to have no effect).

Gonzalez: I was disappointed to see that the carotid bodies on your knockout mice were not hypertrophic. This is surprising at the view of your findings the carotid bodies are permanently activated and that their chemoreceptor cells have permanently high levels of intracellular $\mathrm{Ca}^{2+}$. It is constant activation of chemoreceptors cells what leads to hypertrophy of the carotid bodies in permanent residents at high altitude.

López-Barneo: To have a tumour you probably need to lose the normal allele. We are changing the genetic background of this animal model to see whether in a different background we can get carotid body tumours.

Archer: This is an elegant mouse model, but the problem with the BL6 background is that it doesn't hypertrophy very well. This is a recurring problem with BL6 backgrounds: they don't have a robust remodelling response to vascular injury. If you are failing to see hypertrophy when you are expecting it this might well be the mouse strain-related phenomenon. Although Paul and I don't agree on the effects of hypoxia on pulmonary vascular radical production, we do agree that mitochondria are important as sensors. What is surprising is that when you gave a variety of mitochondrial inhibitors to the carotid body, they caused carotid body discharge, thereby mimicking what hypoxia does, and one of the inhibitors actually ablated subsequent hypoxic responses. Wouldn't the simplest interpretation of these observations be that mitochondria are important in the carotid body's hypoxic response? You attribute the effects to non-specific effects. When you get all those mitochondrial inhibitors and they all cause discharge in the carotid body, wouldn't that point at the mitochondria? I am surprised that your interpretation was that it was not mitochondria. 
López-Barneo: I don't mind interpreting the data a different way, the problem is that I don't know how to do it. The way I interpret these data is that it is unlikely that acute oxygen sensing in the carotid body is associated with mitochondria.

Duchen: With rotenone, one of the things that surprises me is that it doesn't ablate the response to hypoxia, it stops it. Your slope was cumulative and secretion was repressed by rotenone. I don't understand how this works. If rotenone was doing what it does, you'd expect it to continue irrespective of whether you apply hypoxia or not. Why do you get a decrease in secretion? How do you interpret this?

López-Barneo: On average, hypoxia wouldn't decrease secretory activity in rotenone. This occasionally happened but not always. When we used large concentrations of rotenone (say above $1 \mu \mathrm{M}$ ) the effect of rotenone was rather irreversible and after removal of the drug the cells were still insensitive to hypoxia. In these cases hypoxia did not increase secretory activity of the rotenone-treated cells but it did not produce inhibition of secretion either.

Duchen: We did the same experiment many years ago, measuring $\left[\mathrm{Ca}^{2+}\right]$ as an endpoint, and found that all the mitochondrial inhibitors blocked the $\left[\mathrm{Ca}^{2+}\right]$ response to hypoxia.

Chandel: Does FCCP do the same thing?

Duchen: Yes.

Chandel: So why not add FCCP first and then use the mitochondrial inhibitors? This would get rid of the effect the mitochondrial membrane potential might have on $\mathrm{Ca}^{2+}$.

Lopez-Barneo: The problem with glomus cells is that this would probably kill them.

Gonzalez: If you use uncouplers you would have maximal activation of the cells.

Chandel: But you would still see hypoxic activation on top of this.

Gonzalez: I doubt it, particularly if you use the high concentration of uncouplers needed to fully abolish the mitochondrial potential.

Buckler: There have been a number of studies looking at chemoreceptor discharge with antimycin and oligomycin. More recently there has been a study looking at FCCP. (Mulligan et al 1981, Mulligan \& Lahiri 1982, Mosqueria \& Iturriaga 2002). They all seem to find occlusion, i.e. there is little or no effect of hypoxia in the presence of mitochondrial inhibitors.

Duchen: The main difference is the endpoint that is measured.

Schumacker: Your rationale for the SDHD knockout was very clear, but to be fair, the mechanisms that cause tumour formation in cells and those that regulate the oxygen sensing capacity might be very different. It would seem that the appropriate controls would be to look at the homozygous SDHA knockout. You ought to see the same phenotype with the SDHA as with the SDHD if succinate was the mechanism, or if the mechanism was related to a general slow down of Krebs cycle.

López-Barneo: Has the SDHA knockout been done?

Schumacker: No, but there are ES cells. 
Gonzalez: A quick comment. I think that most familial chemodectomas are produced by fibroblasts growth in the carotid bifurcation. Very few chemodectomas in humans are functional, that is, very few chemodectomas are due to proliferation of chemoreceptor cells.

López-Barneo: This might be true. Nevertheless, it is also well known that paragangliomas contain a large number of catecholamine-secreting glomus cells. In fact, they can produce systemic hypertension.

\section{References}

Mosqueria M, Iturriaga R 2002 Carotid body chemosensory excitation induced by nitric oxide: involvement of oxidative metabolism. Respir Physiolo Neurobiol 131:175-187

Mulligan E, Lahiri S 1982 Separation of carotid body chemoreceptor responses to $\mathrm{O}_{2}$ and $\mathrm{CO}_{2}$ by oligomycin and by antimycin A. Am J Physiol 242:C200-206

Mulligan E, Lahiri S, Storey BT 1981 Carotid body $\mathrm{O}_{2}$ chemoreception and mitochondrial oxidative phosphorylation. J Appl Physiol 51:438-446

Wyatt CN, Buckler KJ 2004 The effect of mitochondrial inhibitors on membrane currents in isolated neonatal rat carotid body type I cells. J Physiol 556:175-191 